\title{
Nutrient and Antinutrient Composition of Winged Bean (Psophocarpus tetragonolobus (L.) DC.) Seeds and Tubers
}

\author{
Taofeek T. Adegboyega $\left(\mathbb{D},{ }^{1,2}\right.$ Michael T. Abberton ${ }^{(D)},{ }^{1}$ AbdelAziz H. AbdelGadir, ${ }^{3}$ \\ Mahamadi Dianda, ${ }^{3}$ Busie Maziya-Dixon $\mathbb{D}^{,},{ }^{4}$ Olaniyi A. Oyatomi, ${ }^{1}$ Sam Ofodile, ${ }^{5}$ \\ and Olubukola O. Babalola $\mathbb{D}^{2}$
}

${ }^{1}$ Genetic Resources Center, International Institute of Tropical Agriculture (IITA), Oyo Road, Ibadan, Nigeria

${ }^{2}$ Food Security and Safety Niche Area, Faculty of Natural and Agricultural Sciences, North-West University, Private Bag X2046, Mmabatho 2735, South Africa

${ }^{3}$ Soil Microbiology Laboratory, IITA, Ibadan, Nigeria

${ }^{4}$ Food and Nutrition Sciences Laboratory, IITA, Ibadan, Nigeria

${ }^{5}$ Biometrics Unit, IITA, Ibadan, Nigeria

\begin{abstract}
Correspondence should be addressed to Taofeek T. Adegboyega; t.adegboyega@cgiar.org and Michael T. Abberton; m.abberton@cgiar.org
\end{abstract}

Received 29 April 2019; Revised 13 August 2019; Accepted 30 August 2019; Published 3 October 2019

Academic Editor: Flora V. Romeo

Copyright (C) 2019 Taofeek T. Adegboyega et al. This is an open access article distributed under the Creative Commons Attribution License, which permits unrestricted use, distribution, and reproduction in any medium, provided the original work is properly cited.

\begin{abstract}
Many people in sub-Saharan Africa suffer from protein malnutrition; this results in negative health and economic impacts. Winged bean (Psophocarpus tetragonolobus (L.) DC.) is a tropical underutilized legume with beneficial nutritional characteristics such as high protein content, which may help to alleviate these problems. The proximate composition (fat, moisture content, crude protein, ash, and carbohydrate) and antinutrient (tannin and phytate) level of winged bean seeds and tubers were determined using 50 accessions. In the processed seeds, accession Tpt17 had the highest protein content (40.30\%) and Tpt 48 the lowest (34.18\%). In the unprocessed seeds, Tpt17 also recorded the highest crude protein $(31.13 \%)$ with Tpt125 having the lowest (28.43\%). In the tubers, protein content ranged from 19.07\% (Tpt42) to $12.26 \%$ (Tpt10). The moisture content in the processed seeds ranged from $8.51 \%$ (Tpt42) to 6.72\% (Tpt6); in the unprocessed seeds, it was between $8.53 \%$ (Tpt53) and 3.76\% (Tpt14). In the processed seeds, the values of ash ranged from 4.93\% (Tpt126) to 4.45\% (Tpt15-4); in the unprocessed seeds, it ranged from $4.98 \%$ (Tpt17) to $4.55 \%$ (Tpt125). In the processed seeds, the fat content ranged from $18.91 \%$ (Tpt51) to $14.09 \%$ (Tp43) while in the unprocessed seeds, the values ranged from $19.01 \%$ (Tpt15) to $13.87 \%$ (Tpt3-B). The crude fiber in the processed samples ranged from $13.82 \%$ (Tpt6) to $10.40 \%$ (Tpt125) while in the unprocessed seeds, it ranged from $7.29 \%$ in Tpt51 to $4.83 \%$ in Tpt 11 . Carbohydrate content in the processed seeds ranged from $26.30 \%$ (Tpt3-B) to $20.94 \%$ (Tpt125) and 39.76\% in Tpt3-B to $34.53 \%$ in Tpt18 in the unprocessed seeds. The tannin and phytate contents showed remarkably significant differences. In the tubers harvested, significant variation was observed in the parameters evaluated. Winged bean flour could be formulated into various meals for children and adults to reduce malnutrition in sub-Saharan Africa.
\end{abstract}

\section{Introduction}

Legumes are an essential source of oils and proteins [1]. Winged bean, Psophocarpus tetragonolobus (L.) DC., is primarily considered an orphan crop though it is known for its high yield potential and nutritional value when compared to soybean [2]. It is a lesser-known tropical legume grown in Papua New Guinea and Southeast Asia, mainly in Malaysia [1]. Winged bean seeds contain high dietary protein due to their amino-acid content, substantial protein bioavailability, and low levels of antinutritional factors [3]. Winged bean seeds are generating 
unique research and commercial interest mainly due to their nutritional quality (high proteins and fatty oil content). Plant parts such as flowers, leaves, green pods, and tubers are also suitable for consumption [4].

Knowledge on the nutritional composition of winged bean seeds could help to decipher how the seeds can be used as a substitute for soybean which has similar features. Soybean proteins have been used extensively in food applications [5] and can therefore serve as a reference to evaluate new protein materials $[6,7]$. In this study, seeds and tubers of selected accessions of winged bean were analyzed to evaluate their nutritional and antinutritional composition and document variability between accessions in response to processing. This study is part of the germplasm prebreeding program at the Genetic Resources Center, International Institute of Tropical Agriculture (IITA), aimed at increasing food security and dietary diversification in tropical agriculture.

\section{Materials and Methods}

Standard laboratory methods were used to analyze the seeds and tubers that were processed into flour as described by Alamu et al. [8] for proximate analysis (crude protein, fat, crude fiber, ash, moisture content, and carbohydrate), Adegunwa et al. [9] for tannin determination, and Wheeler and Ferrel [10] for phytic acid analysis. Field-harvested seeds were cleaned and slightly roasted under low heat until they were light brown in color. The roasted grains were coarsemilled and winnowed to remove seed coats. The decorticated grain was milled into fine powder and sieved for processed samples. The unprocessed samples were cleaned and milled until fine flour was obtained. The samples were labelled and stored in airtight containers at $4-6^{\circ} \mathrm{C}$ for analysis. The harvested tubers were peeled, rinsed with water, and ovendried at $60^{\circ} \mathrm{C}$. They were then milled, labelled, and packaged in airtight containers for analysis. The proximate and antinutrient analyses were conducted at the Food and Nutrition Sciences Laboratory (FNSL), IITA, Ibadan, Nigeria. Statistical Analysis Software (SAS, version 9.4) was used to determine the analysis of variance (ANOVA) of data obtained. Table 1 shows the passport data of the accessions used in this study.

\section{Results}

For processed seeds, the moisture content ranged from $8.51 \%$ (Tpt42) to $6.72 \%$ (Tpt6); in the unprocessed seeds, it was between $8.53 \%$ (Tpt53) and $3.76 \%$ (Tpt14). In the processed seeds, the values of ash ranged from Tpt126 (4.93\%) to Tpt15-4 (4.45\%); in the unprocessed seeds, it ranged from Tpt17 (4.98\%) to Tpt125 (4.55\%). In the processed seeds, the fat content was as follows: Tpt51 (18.91\%), Tpt53 (18.79\%), Tpt125 (18.66\%), and the least was in Tpt43 $(14.09 \%)$. In the unprocessed seeds, the values were Tpt15 (19.01\%), Tpt10 (18.50\%), Tpt14 (18.42\%), and the least fat content was recorded in Tpt3-B (13.87\%) (Tables 2 and 3).

Variations were observed in the crude protein content. In the processed seeds, Tpt17 had the highest content of
TABLE 1: Twenty-five accessions of winged bean sourced from GRC, IITA.

\begin{tabular}{lcc}
\hline Accession & Origin & Seed color \\
\hline Tpt2 & No passport data & Light brown \\
Tpt4 & Costa Rica & Dark brown \\
Tpt6 & Indonesia & Light brown \\
Tpt10 & Sri Lanka & Brownish grey \\
Tpt11 & Nigeria & Greyish orange \\
Tpt12 & Sri Lanka & Brown \\
Tpt14 & No passport data & Brown \\
Tpt15 & No passport data & Dark brown \\
Tpt16 & Indonesia & Greyish orange \\
Tpt17 & Trinidad and & Light brown \\
Tpt18 & Tobago & No passport data \\
Tpt19 & Nigeria & Dark brown \\
Tpt30 & No passport data & Brownish orange \\
Tpt32 & Liberia & Brown \\
Tpt33 & No passport data & Light brown \\
Tpt42 & No passport data & Reddish brown \\
Tpt43 & Bangladesh & Dark brown \\
Tpt48 & No passport data & Greyish yellow \\
Tpt51 & Bangladesh & Greyish orange \\
Tpt53 & Nigeria & Dark brown \\
Tpt125 & No passport data & Light brown \\
Tpt126 & Nigeria & Brown \\
Tpt154 & No passport data & Greyish orange \\
Tpt15-4 & No passport data & Reddish blond brownish orange \\
Tpt3-B & No passport data & Yellowish dark blond \\
\hline
\end{tabular}

40.30\%, followed by Tpt11 (39.72\%), Tpt43 (39.35\%), Tpt154 (39.21\%), and Tpt4 (38.88); the lowest was recorded in Tpt48 (34.18\%). In the unprocessed seeds, Tpt17 also recorded the highest crude protein content at $31.13 \%$, followed by Tpt4 (31.02\%), Tpt15-4 (30.84\%), and Tpt42 (30.62\%); the lowest was contained in Tpt125 (28.43\%) (Table 2).

The crude fiber in the processed samples ranged from $13.82 \%$ (Tpt6) to $10.40 \%$ (Tpt125); in the unprocessed seeds, it ranged from $7.29 \%$ in Tpt51 to $4.83 \%$ in Tpt 11 . Relatively low levels of carbohydrate were present in winged bean, unlike African yam bean (Sphenostylis stenocarpa). In the processed seeds, the values obtained ranged from $26.30 \%$ (Tpt3-B) to $20.94 \%$ (Tpt125); the unprocessed seeds showed much higher values of carbohydrate than the processed samples from $39.76 \%$ in Tpt3-B to $34.53 \%$ in Tpt 18 . The tannin content varied among the accessions; in the processed samples, it ranged from $2.57 \%$ (Tpt51) to $1.81 \%$ (Tpt43) and in the unprocessed seeds, from $3.43 \%$ in Tpt32 to $1.36 \%$ in Tpt30 (Table 4). The phytate content also recorded differences, but these were not statistically significant. The highest content of tannins in the processed seeds was found in Tpt19 (9.38\%) and the lowest in Tpt4 (3.78\%); the values ranged from $9.96 \%$ in Tpt42 to $4.09 \%$ in Tpt19 (Table 5). Only moisture content, ash, fat, and crude protein levels were determined in the tubers harvested. The ash content also varied from $3.31 \%$ (Tpt154) to $1.10 \%$ (Tpt43) while the moisture content ranged from $7.81 \%$ in Tpt42 to $1.40 \%$ in Tpt43. Fat content ranged from $4.53 \%$ (Tpt33) to $0.21 \%$ (Tpt16) while the 
TABle 2: Proximate composition (mean \pm standard deviation) of processed seeds of winged bean.

\begin{tabular}{|c|c|c|c|c|c|c|}
\hline Accession & MC (\%) & Ash (\%) & Fat (\%) & CP (\%) & CF (\%) & $\mathrm{CHO}(\%)$ \\
\hline Tpt06 & $6.72 \pm 0.09$ & $4.79 \pm 0.02$ & $17.65 \pm 0.36$ & $36.83 \pm 0.14$ & $13.82 \pm 0.00$ & $20.21 \pm 0.29$ \\
\hline Tpt10 & $6.84 \pm 0.05$ & $4.71 \pm 0.09$ & $16.07 \pm 0.59$ & $37.71 \pm 0.03$ & $11.13 \pm 0.33$ & $23.56 \pm 1.00$ \\
\hline Tpt11 & $6.92 \pm 0.09$ & $4.92 \pm 0.00$ & $14.91 \pm 0.02$ & $39.72 \pm 0.35$ & $10.79 \pm 0.59$ & $22.76 \pm 0.17$ \\
\hline Tpt12 & $6.89 \pm 0.20$ & $4.75 \pm 0.03$ & $17.38 \pm 0.59$ & $35.08 \pm 0.13$ & $9.88 \pm 0.09$ & $26.03 \pm 0.33$ \\
\hline Tpt125 & $8.38 \pm 0.08$ & $4.87 \pm 0.00$ & $18.66 \pm 0.35$ & $36.76 \pm 0.05$ & $10.4 \pm 0.11$ & $20.94 \pm 0.60$ \\
\hline Tpt126 & $8.10 \pm 0.08$ & $4.93 \pm 0.06$ & $15.01 \pm 1.05$ & $38.29 \pm 0.34$ & $11.47 \pm 0.58$ & $22.20 \pm 1.94$ \\
\hline Tpt14 & $6.78 \pm 0.04$ & $4.68 \pm 0.01$ & $15.59 \pm 0.11$ & $37.80 \pm 0.22$ & $11.64 \pm 0.66$ & $23.52 \pm 0.61$ \\
\hline Tpt15 & $6.75 \pm 0.01$ & $4.65 \pm 0.03$ & $15.14 \pm 0.49$ & $37.51 \pm 0.16$ & $10.62 \pm 0.39$ & $25.34 \pm 1.06$ \\
\hline Tpt15-4 & $8.34 \pm 0.12$ & $4.45 \pm 0.59$ & $15.71 \pm 1.35$ & $39.21 \pm 0.10$ & $11.02 \pm 0.37$ & $21.29 \pm 0.41$ \\
\hline Tpt16 & $6.77 \pm 0.01$ & $4.80 \pm 0.04$ & $16.16 \pm 0.14$ & $36.26 \pm 0.08$ & $10.73 \pm 0.04$ & $25.29 \pm 0.04$ \\
\hline Tpt17 & $6.97 \pm 0.02$ & $4.88 \pm 0.06$ & $16.21 \pm 0.06$ & $40.30 \pm 0.02$ & $10.60 \pm 0.46$ & $21.06 \pm 0.47$ \\
\hline Tpt18 & $6.72 \pm 0.04$ & $4.65 \pm 0.03$ & $17.12 \pm 0.49$ & $36.30 \pm 0.08$ & $10.87 \pm 0.59$ & $24.36 \pm 0.19$ \\
\hline Tpt19 & $8.10 \pm 0.21$ & $4.61 \pm 0.06$ & $16.63 \pm 0.02$ & $36.01 \pm 0.47$ & $10.96 \pm 0.01$ & $23.70 \pm 0.58$ \\
\hline Tpt2 & $6.74 \pm 0.03$ & $4.91 \pm 0.08$ & $17.65 \pm 1.49$ & $35.23 \pm 0.22$ & $11.75 \pm 0.34$ & $23.74 \pm 1.04$ \\
\hline Tpt3-B & $7.69 \pm 0.33$ & $4.67 \pm 0.17$ & $17.60 \pm 0.16$ & $36.25 \pm 0.13$ & $7.50 \pm 0.65$ & $26.30 \pm 0.14$ \\
\hline TPt30 & $8.05 \pm 0.04$ & $4.78 \pm 0.08$ & $16.18 \pm 0.21$ & $36.24 \pm 0.11$ & $11.14 \pm 0.43$ & $23.63 \pm 0.45$ \\
\hline Tpt32 & $8.35 \pm 0.16$ & $4.73 \pm 0.02$ & $14.21 \pm 0.22$ & $38.70 \pm 0.12$ & $10.99 \pm 0.11$ & $23.05 \pm 0.35$ \\
\hline Tpt33 & $8.26 \pm 0.02$ & $4.60 \pm 0.33$ & $16.59 \pm 0.10$ & $36.81 \pm 0.21$ & $10.15 \pm 0.18$ & $23.60 \pm 0.28$ \\
\hline Tpt4 & $6.72 \pm 0.16$ & $4.75 \pm 0.06$ & $16.20 \pm 0.60$ & $38.88 \pm 0.04$ & $11.13 \pm 0.29$ & $22.34 \pm 0.75$ \\
\hline Tpt42 & $8.51 \pm 0.33$ & $4.54 \pm 0.06$ & $17.12 \pm 1.56$ & $36.48 \pm 0.21$ & $12.12 \pm 0.82$ & $21.24 \pm 1.8$ \\
\hline Tpt43 & $8.51 \pm 0.03$ & $4.60 \pm 0.21$ & $14.09 \pm 0.10$ & $39.35 \pm 0.02$ & $11.41 \pm 0.33$ & $22.06 \pm 0.64$ \\
\hline Tpt48 & $8.11 \pm 0.09$ & $4.61 \pm 0.31$ & $15.75 \pm 0.37$ & $34.18 \pm 0.69$ & $11.18 \pm 0.30$ & $26.19 \pm 0.42$ \\
\hline Tpt51 & $8.17 \pm 0.04$ & $4.63 \pm 0.08$ & $18.91 \pm 1.91$ & $36.24 \pm 0.45$ & $11.94 \pm 1.39$ & $20.12 \pm 0.19$ \\
\hline Tpt53 & $8.31 \pm 0.10$ & $4.63 \pm 0.06$ & $18.79 \pm 0.47$ & $34.33 \pm 0.40$ & $11.15 \pm 0.19$ & $22.80 \pm 0.21$ \\
\hline LSD & 0.28 & 0.34 & 1.74 & 0.52 & 1.03 & 1.91 \\
\hline$F$ value & $59.73^{* * *}$ & $1.16^{\text {ns }}$ & $5.09^{* * *}$ & $85.81^{* * *}$ & $8.97^{* * *}$ & $7.49^{* * *}$ \\
\hline
\end{tabular}

Note. $F$ values represent one-way ANOVA, degrees of freedom $(\mathrm{df})=24 .{ }^{* * *} p<0.0001 . \mathrm{MC}=$ moisture content; $\mathrm{CP}=\mathrm{crude}$ protein; $\mathrm{CF}=\mathrm{crude}$ fiber; $\mathrm{CHO}=$ carbohydrate; $\mathrm{ns}=$ not significant; $\mathrm{Tpt}=$ tropical Psophocarpus tetragonolobus .

TABLE 3: Tannin and phytate concentration (mean \pm standard deviation) of processed winged bean seeds.

\begin{tabular}{|c|c|c|}
\hline Accession & Tannin (\%) & Phytate $(\mathrm{mg} / 100 \mathrm{~g})$ \\
\hline Tpt06 & $1.79 \pm 0.40$ & $5.05 \pm 0.09$ \\
\hline Tpt10 & $1.95 \pm 0.07$ & $6.73 \pm 0.10$ \\
\hline Tpt11 & $2.01 \pm 0.29$ & $8.07 \pm 0.09$ \\
\hline Tpt12 & $1.98 \pm 0.03$ & $8.70 \pm 0.04$ \\
\hline Tpt125 & $2.38 \pm 0.14$ & $8.56 \pm 0.09$ \\
\hline Tpt126 & $2.23 \pm 0.47$ & $9.26 \pm 0.15$ \\
\hline Tpt14 & $2.03 \pm 0.06$ & $8.17 \pm 0.05$ \\
\hline Tpt15 & $2.05 \pm 0.16$ & $7.57 \pm 0.05$ \\
\hline Tpt15-4 & $2.25 \pm 0.04$ & $8.09 \pm 0.09$ \\
\hline Tpt154 & $2.32 \pm 0.18$ & $5.74 \pm 0.09$ \\
\hline Tpt16 & $1.89 \pm 0.03$ & $8.71 \pm 0.05$ \\
\hline Tpt17 & $2.52 \pm 0.12$ & $6.73 \pm 0.09$ \\
\hline Tpt18 & $2.16 \pm 0.11$ & $9.24 \pm 0.00$ \\
\hline Tpt19 & $1.93 \pm 0.11$ & $9.38 \pm 0.05$ \\
\hline Tpt2 & $1.88 \pm 0.24$ & $5.28 \pm 0.05$ \\
\hline Tpt3-B & $2.22 \pm 0.50$ & $7.05 \pm 0.05$ \\
\hline Tpt30 & $1.69 \pm 0.02$ & $9.25 \pm 0.09$ \\
\hline Tpt32 & $1.94 \pm 0.12$ & $9.36 \pm 0.10$ \\
\hline Tpt33 & $1.99 \pm 0.18$ & $8.32 \pm 0.09$ \\
\hline Tpt4 & $2.40 \pm 0.43$ & $3.78 \pm 0.10$ \\
\hline Tpt42 & $2.31 \pm 0.18$ & $7.01 \pm 0.05$ \\
\hline Tpt43 & $1.81 \pm 0.29$ & $7.60 \pm 0.05$ \\
\hline Tpt48 & $2.49 \pm 0.00$ & $6.73 \pm 0.11$ \\
\hline Tpt51 & $2.57 \pm 0.23$ & $8.89 \pm 0.10$ \\
\hline Tpt53 & $2.48 \pm 0.14$ & $9.16 \pm 0.01$ \\
\hline LSD & 0.37 & 0.17 \\
\hline$F$ value & $4.47^{* *}$ & $661.01^{* * *}$ \\
\hline
\end{tabular}

Note. $F$ values represent one-way ANOVA, degrees of freedom $(\mathrm{df})=24 .{ }^{* * *} p<0.0001 ;{ }^{* *} p<0.001 . \mathrm{Tpt}=$ tropical Psophocarpus tetragonolobus. 
TABle 4: Proximate composition (mean \pm standard deviation) of unprocessed seeds of winged bean.

\begin{tabular}{|c|c|c|c|c|c|c|}
\hline Accession & MC (\%) & Ash (\%) & Fat (\%) & CP (\%) & CF (\%) & $\mathrm{CHO}(\%)$ \\
\hline Tpt06 & $4.74 \pm 0.10$ & $4.78 \pm 0.04$ & $17.76 \pm 0.29$ & $29.88 \pm 0.22$ & $5.49 \pm 0.0$ & $37.34 \pm 0.15$ \\
\hline Tpt10 & $4.63 \pm 0.11$ & $4.75 \pm 0.02$ & $18.50 \pm 0.29$ & $29.69 \pm 0.10$ & $5.43 \pm 0.14$ & $37.00 \pm 0.44$ \\
\hline Tpt11 & $4.75 \pm 0.02$ & $4.73 \pm 0.15$ & $18.28 \pm 0.42$ & $29.55 \pm 0.93$ & $4.83 \pm 0.02$ & $37.87 \pm 0.66$ \\
\hline Tpt12 & $5.45 \pm 0.10$ & $4.87 \pm 0.02$ & $18.35 \pm 0.30$ & $30.47 \pm 0.10$ & $5.18 \pm 0.22$ & $35.67 \pm 0.53$ \\
\hline Tpt125 & $7.19 \pm 0.28$ & $4.55 \pm 0.08$ & $15.76 \pm 0.91$ & $28.43 \pm 0.52$ & $6.26 \pm 0.36$ & $37.82 \pm 1.43$ \\
\hline Tpt126 & $7.37 \pm 0.04$ & $4.59 \pm 0.00$ & $17.84 \pm 0.18$ & $28.68 \pm 0.01$ & $6.29 \pm 0.33$ & $35.24 \pm 0.21$ \\
\hline Tpt14 & $3.76 \pm 0.07$ & $4.88 \pm 0.01$ & $18.42 \pm 1.27$ & $30.47 \pm 0.05$ & $5.93 \pm 0.20$ & $36.54 \pm 1.06$ \\
\hline Tpt15 & $4.05 \pm 0.06$ & $4.71 \pm 0.01$ & $19.01 \pm 0.02$ & $29.41 \pm 0.06$ & $5.71 \pm 0.10$ & $37.11 \pm 0.11$ \\
\hline Tpt15-4 & $5.34 \pm 0.01$ & $4.93 \pm 0.05$ & $17.75 \pm 0.18$ & $30.84 \pm 0.32$ & $5.78 \pm 0.11$ & $35.37 \pm 0.29$ \\
\hline Tpt16 & $4.62 \pm 0.19$ & $4.77 \pm 0.09$ & $18.27 \pm 0.11$ & $29.82 \pm 0.55$ & $3.09 \pm 4.36$ & $18.43 \pm 26.06$ \\
\hline Tpt17 & $4.07 \pm 0.01$ & $4.98 \pm 0.15$ & $18.33 \pm 0.06$ & $31.13 \pm 0.93$ & SNE & SNE \\
\hline Tpt18 & $5.97 \pm 0.26$ & $4.76 \pm 0.17$ & $18.14 \pm 0.04$ & $29.74 \pm 1.07$ & $6.86 \pm 0.03$ & $34.52 \pm 1.06$ \\
\hline Tpt19 & $7.45 \pm 0.06$ & $4.69 \pm 0.04$ & $15.99 \pm 0.31$ & $29.33 \pm 0.26$ & $4.61 \pm 0.08$ & $37.94 \pm 0.02$ \\
\hline Tpt2 & $5.12 \pm 0.07$ & $4.87 \pm 0.02$ & $17.81 \pm 0.04$ & $30.25 \pm 0.10$ & $5.70 \pm 0.00$ & $36.26 \pm 0.18$ \\
\hline Tpt3-B & $6.55 \pm 0.25$ & $4.66 \pm 0.06$ & $13.87 \pm 0.49$ & $29.10 \pm 0.37$ & $6.06 \pm 0.34$ & $39.76 \pm 0.33$ \\
\hline TPt30 & $5.29 \pm 0.01$ & $4.75 \pm 0.05$ & $17.09 \pm 0.56$ & $29.72 \pm 0.31$ & $4.99 \pm 0.03$ & $38.16 \pm 0.90$ \\
\hline Tpt32 & $6.16 \pm 0.00$ & $4.72 \pm 0.05$ & $17.12 \pm 0.24$ & $29.47 \pm 0.30$ & $6.19 \pm 0.37$ & $36.35 \pm 0.95$ \\
\hline Tpt33 & $6.15 \pm 0.14$ & $4.72 \pm 0.05$ & $17.09 \pm 0.55$ & $29.48 \pm 0.33$ & SNE & SNE \\
\hline Tpt4 & $5.77 \pm 0.05$ & $4.96 \pm 0.01$ & $18.39 \pm 0.02$ & $31.02 \pm 0.06$ & $5.22 \pm 0.08$ & $34.63 \pm 0.17$ \\
\hline Tpt42 & $5.89 \pm 0.02$ & $4.90 \pm 0.05$ & $16.47 \pm 0.61$ & $30.61 \pm 0.32$ & $6.61 \pm 0.60$ & $35.52 \pm 0.81$ \\
\hline Tpt43 & $6.67 \pm 0.07$ & $4.63 \pm 0.10$ & $17.28 \pm 0.13$ & $28.93 \pm 0.65$ & $5.85 \pm 0.01$ & $36.64 \pm 0.96$ \\
\hline Tpt48 & $6.90 \pm 0.03$ & $4.57 \pm 0.14$ & $17.44 \pm 0.43$ & $28.54 \pm 0.85$ & $6.83 \pm 0.46$ & $35.71 \pm 0.07$ \\
\hline Tpt51 & $6.26 \pm 0.03$ & $4.69 \pm 0.10$ & $15.82 \pm 0.12$ & $29.34 \pm 0.61$ & $7.28 \pm 0.07$ & $36.61 \pm 0.79$ \\
\hline Tpt53 & $8.53 \pm 0.08$ & $4.64 \pm 0.10$ & $17.17 \pm 0.70$ & $29.00 \pm 0.65$ & $6.60 \pm 0.32$ & $34.06 \pm 0.45$ \\
\hline LSD & 0.24 & 0.18 & 0.98 & 1.14 & 1.89 & 11.05 \\
\hline$F$ value & $223.09^{* * *}$ & $3.95^{* *}$ & $11.48^{* * *}$ & $3.89^{* *}$ & $5.19^{* * *}$ & $4.78^{* *}$ \\
\hline
\end{tabular}

Note. $F$ values represent one-way ANOVA, degrees of freedom $(\mathrm{df})=24 .{ }^{* * *} p<0.0001 . \mathrm{MC}=$ moisture content; $\mathrm{CP}=\mathrm{crude}$ protein; $\mathrm{CF}=\mathrm{crude}$ fiber; $\mathrm{CHO}=$ carbohydrate; $\mathrm{Tpt}=$ tropical Psophocarpus tetragonolobus; $\mathrm{SNE}=$ sample not enough.

TABLE 5: Tannin and phytate concentration (means \pm standard deviation) of unprocessed seeds.

\begin{tabular}{|c|c|c|}
\hline Accession & Tannin (\%) & Phytate $(\mathrm{mg} / 100 \mathrm{~g})$ \\
\hline Tpt06 & $1.76 \pm 0.24$ & $8.65 \pm 0.14$ \\
\hline Tpt10 & $2.55 \pm 0.23$ & $6.61 \pm 0.09$ \\
\hline Tpt11 & $2.55 \pm 0.09$ & $5.83 \pm 0.05$ \\
\hline Tpt12 & $2.33 \pm 0.25$ & $8.25 \pm 0.05$ \\
\hline Tpt125 & $1.92 \pm 0.05$ & $7.11 \pm 0.05$ \\
\hline Tpt126 & $1.92 \pm 0.16$ & $7.45 \pm 0.05$ \\
\hline Tpt14 & $2.41 \pm 0.20$ & $5.96 \pm 0.05$ \\
\hline Tpt15 & $2.76 \pm 0.33$ & $5.75 \pm 0.05$ \\
\hline Tpt15-4 & $1.82 \pm 0.23$ & $8.28 \pm 0.10$ \\
\hline Tpt154 & $1.92 \pm 0.18$ & $9.02 \pm 0.10$ \\
\hline Tpt16 & $2.56 \pm 0.08$ & $8.37 \pm 0.05$ \\
\hline Tpt17 & $2.94 \pm 0.28$ & $6.27 \pm 0.00$ \\
\hline Tpt18 & $2.45 \pm 0.03$ & $5.76 \pm 0.05$ \\
\hline Tpt19 & $1.39 \pm 0.23$ & $4.09 \pm 0.14$ \\
\hline Tpt2 & $2.25 \pm 0.30$ & $6.67 \pm 0.09$ \\
\hline Tpt3-B & $2.70 \pm 0.39$ & $8.95 \pm 0.00$ \\
\hline Tpt30 & $1.36 \pm 0.09$ & $5.59 \pm 0.09$ \\
\hline Tpt32 & $3.43 \pm 0.04$ & $6.84 \pm 0.05$ \\
\hline Tpt33 & $2.81 \pm 0.01$ & $9.41 \pm 0.09$ \\
\hline Tpt4 & $2.52 \pm 0.02$ & $9.11 \pm 0.03$ \\
\hline Tpt42 & $1.96 \pm 0.07$ & $9.96 \pm 0.10$ \\
\hline Tpt43 & $2.59 \pm 0.11$ & $9.09 \pm 0.10$ \\
\hline Tpt48 & $1.71 \pm 0.11$ & $9.06 \pm 0.05$ \\
\hline Tpt51 & $2.89 \pm 0.03$ & $7.48 \pm 0.09$ \\
\hline Tpt53 & $1.72 \pm 0.22$ & $7.62 \pm 0.09$ \\
\hline LSD & 0.38 & 0.16 \\
\hline$F$ value & $16.03^{* * *}$ & $772.36^{* * *}$ \\
\hline
\end{tabular}

Notes. $F$ values represent one-way ANOVA, degrees of freedom $(\mathrm{df})=24 .{ }^{* * *} p<0.0001 . \mathrm{Tpt}=$ tropical Psophocarpus tetragonolobus. 
TABLE 6: Percentage nutrient (mean \pm standard deviation) of flours from winged bean tubers.

\begin{tabular}{lcccc}
\hline Accession & MC (\%) & Ash (\%) & Fat (\%) & Protein (\%) \\
\hline Tpt10 & $6.83 \pm 0.08$ & $2.66 \pm 0.03$ & $0.53 \pm 0.05$ & $12.26 \pm 0.28$ \\
Tpt11 & $7.13 \pm 0.12$ & $2.62 \pm 0.16$ & $0.49 \pm 0.05$ & $17.29 \pm 0.29$ \\
Tpt12 & $7.79 \pm 0.08$ & $1.89 \pm 0.36$ & $0.90 \pm 0.54$ & $16.10 \pm 0.03$ \\
Tpt125 & $5.76 \pm 0.07$ & $2.35 \pm 0.04$ & $0.53 \pm 0.08$ & $16.21 \pm 0.06$ \\
Tpt126 & $5.94 \pm 0.04$ & $2.36 \pm 0.02$ & $0.23 \pm 0.06$ & $15.51 \pm 0.13$ \\
Tpt15 & $7.11 \pm 0.03$ & $2.20 \pm 0.05$ & $0.38 \pm 0.10$ & $15.34 \pm 0.18$ \\
Tpt15-4 & $6.96 \pm 0.04$ & $2.43 \pm 0.02$ & $0.31 \pm 0.29$ & $14.29 \pm 0.33$ \\
Tpt154 & $4.67 \pm 0.16$ & $3.31 \pm 0.03$ & $0.34 \pm 0.20$ & $14.85 \pm 0.02$ \\
Tpt16 & $6.16 \pm 0.27$ & $2.92 \pm 0.01$ & $0.43 \pm 0.00$ & $16.44 \pm 0.32$ \\
Tpt18 & $7.67 \pm 0.04$ & $2.13 \pm 0.06$ & $0.41 \pm 0.04$ & $16.41 \pm 0.14$ \\
Tpt19 & $6.99 \pm 0.11$ & $2.37 \pm 0.00$ & $0.45 \pm 0.09$ & $16.22 \pm 0.23$ \\
Tpt2 & $6.63 \pm 0.00$ & $3.13 \pm 0.00$ & $0.45 \pm 0.01$ & $12.44 \pm 0.02$ \\
Tpt3-B & $7.81 \pm 0.04$ & $2.59 \pm 0.00$ & $0.51 \pm 0.02$ & $13.61 \pm 0.30$ \\
Tpt30 & $7.23 \pm 0.00$ & $2.78 \pm 0.03$ & $1.17 \pm 1.00$ & SNE \\
Tpt32 & $6.51 \pm 0.00$ & $2.54 \pm 0.00$ & SNE & $15.01 \pm 0.57$ \\
Tpt33 & $6.96 \pm 0.30$ & $2.63 \pm 0.10$ & $4.53 \pm 0.21$ & $15.80 \pm 0.88$ \\
Tpt4 & $6.82 \pm 0.13$ & $2.76 \pm 0.02$ & $0.54 \pm 0.13$ & $17.38 \pm 0.10$ \\
Tpt42 & $7.69 \pm 0.07$ & $3.07 \pm 0.00$ & $4.38 \pm 0.17$ & $19.07 \pm 0.02$ \\
Tpt43 & $2.80 \pm 0.00$ & $2.19 \pm 0.00$ & SNE & SNE \\
Tpt48 & $6.10 \pm 0.03$ & $2.04 \pm 0.06$ & $1.04 \pm 0.77$ & $14.38 \pm 0.16$ \\
Tpt51 & $5.45 \pm 0.09$ & $2.96 \pm 0.00$ & $0.55 \pm 0.00$ & $14.69 \pm 0.34$ \\
Tpt53 & $5.26 \pm 0.01$ & $2.40 \pm 0.00$ & $0.51 \pm 0.05$ & $14.41 \pm 0.53$ \\
Tpt6 & $6.70 \pm 0.12$ & $3.03 \pm 0.05$ & $0.49 \pm 0.07$ & $16.01 \pm 0.04$ \\
\hline LSD & 0.45 & 0.18 & 0.57 & 0.72 \\
$F$ value & $134.48^{* * *}$ & $19.4^{* * *}$ & $26.63^{* * *}$ & $54.89^{* * *}$ \\
\hline Nos. & & & &
\end{tabular}

Notes. $F$ values represent one-way ANOVA, degrees of freedom $(\mathrm{df})=22$. ${ }^{* * *} p<0.0001 . \quad \mathrm{MC}=$ moisture content; $\mathrm{SNE}=$ sample not enough; $\mathrm{Tpt}=$ tropical Psophocarpus tetragonolobus.

protein content ranged from $19.07 \%$ (Tpt42) to $12.26 \%$ (Tpt10) (Table 6).

\section{Discussion}

In the present study, crude protein content ranged from $40.30 \%$ (Tpt17) to $38.88 \%$ (Tpt4) for processed seeds and $31.13 \%$ in Tpt 17 to $28.43 \%$ (Tpt125) which are higher than results previously obtained for cowpea $(22.5 \%)$, pigeon pea (22.4\%), and lima beans (23.3\%) but similar to the results for soybeans $(35 \%)$ [11-13]. The values were also higher than the $14.70 \%$ [14] and $12.86 \%$ [15] previously reported for wheat flour. The differences may be linked to the geographical location of the germplasm collected since high nitrogen level in the soil can influence protein level [16]. The protein content of the flours suggests that they may be useful in food formulation systems which can be improved by blending with wheat or cowpea flour and used as composite flours. In the tubers, the result ranged from $19.07 \%$ (Tpt42) to $12.26 \%$ (Tpt10) which shows that winged bean contains a substantial amount of protein in its tubers. Our results are similar to the findings of Kantha and Erdman [17] who reported the protein content of winged beans to be in the range of $17-19 \%$. We suggest that winged bean seed and tubers are potential sources of protein. The high protein content positions the crop to play a significant role in improving the nutritional status in tropical agriculture.
The values obtained for crude fat were higher (18.91\% (Tpt51) to $14.09 \%(\mathrm{Tpt} 43)$ ) in processed seeds and $19.01 \%$ (Tpt15) to $13.87 \%$ (Tpt3-B) in unprocessed seeds. These figures are higher than that reported by Singh et al. [18], who recorded a crude fat content of $0.47 \%$ in the fully mature seeds. They are however similar to those of previous studies that reported 15-20.4\% [19] and those of other legumes such as chickpea (5.76-6.87\%) as reported by Boye et al. [20]. The result obtained for the tubers (Table 5) ranged from 0.21 (Tpt16) to 4.53 (Tpt33). Due to its high thermal conductivity and oxidative features, winged bean oil is valuable as a frying medium when compared to soybean oil [21]. However, winged bean oil has more saturated fatty acids, thereby making it less preferred. A recent study of the physicochemical properties of winged bean oil found that fatty oil extraction using hexane, which is the most common industrial extraction process, agrees with all edible characteristics and fatty acid compositions [21]. In another study, winged bean oil was superior to soybean oil as a result of its high oxidative strength, solid fat content, and good thermal conductivity, thereby making it suitable for frying food [21].

Winged bean seeds are rich in carbohydrates. The unprocessed seeds contained higher carbohydrate content (39.76-34.53\%) than the processed seeds (26.30-20.94\%). These results are similar to those of previous studies that reported between 23 and 40\% [4,22] and $28.87 \pm 0.45$ in a study conducted by Wan Mohtar et al. [3], but low when compared to other studies involving cowpea and wheat flours, where values ranged from $57.35 \%$ to $83.60 \%$ [23] with wheat flour having the highest carbohydrate content $(83.60 \%)$. In this study, the carbohydrate content of the flours cannot be compared to that of cowpea (57.17\%) and wheat flours (74.22\%) reported by Ahmed et al. [24]. Adukpo, Agbemafle [25] recorded a higher range of carbohydrate content (34.97 to $39.86 \%$ ) for three soybean varieties. High carbohydrate content in legumes suggests that legumes can be used to manage protein-energy malnutrition since they have enough carbohydrate for energy such that the protein can be used for its primary function of body building and repair of worn tissues [26]. Carbohydrates are a good source of energy and are desired in high concentrations in breakfast meals and weaning formulas. The moderate carbohydrate content of winged bean flour can make it a good source of energy in breakfast formulations [26].

Crude fiber in the processed samples ranged from $13.82 \%$ (Tpt6) to $10.40 \%$ (Tpt125); in the unprocessed seeds, it ranged from $7.29 \%$ in Tpt51 to $4.83 \%$ in Tpt 11 . These results are consistent with that of Singh et al. [18] who recorded a crude fiber content of $12.65 \%$ in fully mature seeds and $2.76 \%$ in tubers. The values obtained for winged bean flour were higher than what Leach et al. [27] reported for brown rice flour $(1.23 \%)$ and refined wheat flour $(0.85 \%)$. The results obtained in this study were higher than the $0.85 \%$ reported by Leach et al. [27]. David et al. [23] reported that Asomdwee cowpea flour had the highest crude fiber content (3.21\%). Chinma and Gernah [28] reported a crude fiber content of $8.19 \%$ for pigeon pea, 9.58\% for cowpea, and $4.61 \%$ for mungbean flour. These 
were all lower and slightly comparable to the crude fiber content obtained for the flours in this study. In human health, crude fiber helps to prevent heart diseases, colon cancer, and diabetes, among others. Therefore, it will be useful if winged bean flour is used in food formulations to help relieve constipation.

The moisture content of processed and unprocessed seeds differed significantly. Results showed that the moisture content of processed and unprocessed seeds was lower than the $9.20 \%$ reported by Olalekan and Bosede [29] for cowpea flours in Nigeria. In the tubers, it ranged between 1.4 (Tpt43) and $7.81 \%$ (Tpt3-B). The moisture content was within the acceptable limit of not more than $10 \%$ for long-term storage of flour [30]. It is influenced by type, variety, and storage condition of the material stored [31]. The low moisture content of winged bean flour may enhance its storage stability by preventing microbial growth and other biochemical reactions [30]. Sui et al. [32] reported a moisture content of $7.75 \%$ for wheat flour, which was within the values obtained in this study. This may explain why winged bean may have a longer shelf life and also confirms its usefulness in bakery products. According to Islam et al. [33] bakery products should have an adequate shelf life without any microbiological deterioration, and therefore the low moisture content of the soft-winged bean flour will in the end extend the shelf life of the final product.

The ash content of the flours ranged between 4.98\% (Tpt17) and 4.55\% (Tpt125) for unprocessed flour and from $4.93 \%$ (Tpt126) to $4.45 \%$ (Tpt15-4) in the processed flour. In the tubers, it ranged between 1.1\% (Tpt43) and 3.31\% (Tpt154) (Table 5). The ash content for winged bean flour in this study was higher than the $2.53 \%$ for mung bean flour, $2.53 \%$ for chickpea flour, $4.58 \%$ for pigeon pea, $4.73 \%$ for cowpea, and 3.25\% for mucuna bean flour [29]. Ash content is an indication of the mineral content of food; it therefore suggests that winged bean flour could be a more important source of minerals than cowpea, mung bean, pigeon pea, and mucuna flours.

Despite all the positive nutrition benefits offered by winged bean, antinutritive factors (ANFs) also exist such as tannins, lectins, flatulence factors, phytoglutenins, saponins, and cyanogenic glycosides [34]. The use of moist heat or soaking has been shown to safely eliminate these substances without reduction in their nutritional composition. The presence of antinutrients in foods preparations particularly for children could hinder the efficient utilization and digestion of some nutrients and therefore reduce their bioavailability but may have beneficial effects on adults [2]. For example, research effort has yielded important milestone concerning trypsin, which act to hydrolyze proteins as part of the vertebrate digestion, and trypsin inhibitors, proteins that stop the action of trypsin whose action interfere with digestion. It has been suggested that trypsin inhibitors play a significant role in protecting plant tissues against bacterial proteases at the point where the pathogenic bacteria colonizes the host [35]. In addition, studies indicate the involvement of trypsin in defense against insects that suck the phloem sap and against bacteria that invade whenever there is wound [36]. Furthermore, in biomedical research, these modes of action have made trypsin and trypsin inhibitors significant part of molecular cell research, where they are strongly used in cell culture to remove cells from tissue culture plates [37, 38].

Tannins have been described to have cross-linked with proteins and caused a reduction in in vitro protein digestion of beans [39-42]. They have also been implicated in the inhibition of digestive enzymes, increased excretion of endogenous protein, and effect on digestive tract [39].

Phytate is another important antinutrient factor commonly found in legume seeds. It is an antioxidant that binds to some dietary minerals, interfering with their availability [34]. In this study, the phytate level ranged from 3.78 (Tpt4) to 9.38 (Tpt19) for processed seeds and from 4.09 (Tpt19) to 9.96 (Tpt42) in the unprocessed seeds. Phytate content in winged bean is estimated to be between 6.1 and $7.5 \mathrm{mg}$ of phytate phosphorus per gram of beans, equal to that of soybean. Like many beans, winged bean possesses free phenolics, tannins, phytic acid, flatulence factors, saponins, and hydrogen cyanide. Some of these, especially tannins and phenolic compounds, nonspecifically inhibit enzyme activity and form a complex with food proteins, thus reducing their quality [43].

The tannin level ranges from 1.69 (Tpt30) to 2.57 (Tpt51) for processed seeds and from 1.36 (Tpt30) to 3.43 (Tpt32) in the unprocessed seeds, which is higher than the estimates of another study from 0.03 to $7.5 \mathrm{mg}$ of beans [34]. Notwithstanding, the levels of phytate, etc., are not significant enough to cause adverse effects. Considering that most of these ANFs are destroyed by boiling or autoclaving [34], properly processed winged bean can be safely used as a major plant protein source. Overall, the proximate and antinutritional assessments of winged bean seeds and tubers were similar to those of previous studies of the crop and other similar crops [12, 19, 21, 44-47].

\section{Conclusion}

This study proved that there are variations in the nutritional and antinutritional values of winged bean. The protein content was very high and compares well with that of other legumes, and it could replace them in meals for protein enrichment. These protein levels indicate that winged bean, in particular, could be a replacement in various food formulations where soybean has been used. The crude fiber content of the seeds was higher than that of most other legumes, which indicated that the seeds are positioned as a functional food with health benefits associated with both soluble and insoluble fiber. We also observed that the antinutritional composition was low. The results showed that winged bean flour has the potential to be incorporated into food formulations as a functional ingredient.

\section{Data Availability}

The data used to support the findings of this study are available from the corresponding author upon request. 


\section{Conflicts of Interest}

The authors declare no conflicts of interest.

\section{Acknowledgments}

The authors appreciate the management and staff of GRC, IITA, Ibadan, Nigeria, for the award of a doctoral research fellowship and the North-West University, Republic of South Africa, for the provision of an institutional bursary to the first author. Special appreciation to Dr. Emmanuel Alamu (IITA-Zambia), Mrs. Y. Olatunbosun, and Mr. Juba Adegboyega (IITA Communications Unit) for their assistance in the proof reading and formatting of the manuscript. We are also deeply grateful to the staff of the Food and Nutrition Sciences (FNSL) and Soil Microbiology laboratories of IITA for analyzing and processing the samples. The work of the Genetic Resources Center (GRC), IITA, is funded by the Global Crop Diversity Trust and CGIAR.

\section{References}

[1] T. K. Lim, Edible Medicinal and Non-edicinal Plants, vol. 1, Springer, Berlin, Germany, 2012.

[2] M. Vatanparast, P. Shetty, R. Chopra et al., "Transcriptome sequencing and marker development in winged bean (Psophocarpus tetragonolobus; Leguminosae)," Scientific Reports, vol. 6, no. 1, Article ID 29070, 2016.

[3] W. A. A.-Q. I. Wan Mohtar, A. A. Hamid, S. Abd-Aziz, S. K. Syed Muhamad, and N. Saari, "Preparation of bioactive peptides with high angiotensin converting enzyme inhibitory activity from winged bean (Psophocarpus tetragonolobus (L.) DC.) seed," Journal of Food Science and Technology, vol. 51, no. 12, pp. 3658-3668, 2014.

[4] C. S. Mohanty, R. C. Pradhan, V. Singh et al., "Physicochemical analysis of Psophocarpus tetragonolobus (L.) DC seeds with fatty acids and total lipids compositions," Journal of Food Science and Technology, vol. 52, no. 6, pp. 3660-3670, 2015.

[5] M. Kojima, N. Tachibana, T. Yamahira et al., "Structured triacylglycerol containing behenic and oleic acids suppresses triacylglycerol absorption and prevents obesity in rats," Lipids in Health and Disease, vol. 9, no. 1, p. 77, 2010.

[6] D. Firestone, AOCS Official Methods and Recommended Practices of the AOCS, AOCS, Urbana, IL, USA, 2009.

[7] S. Saadi, A. A. Ariffin, H. M. Ghazali, M. S. Miskandar, H. C. Boo, and S. M. Abdulkarim, "Application of differential scanning calorimetry (DSC), HPLC and pNMR for interpretation primary crystallisation caused by combined low and high melting TAGs," Food Chemistry, vol. 132, no. 1, pp. 603-612, 2012.

[8] A. E. Oladeji, M.-D. Bussie, P. Ibironke, G. Therese, and C. David, "Nutritional evaluation and consumer preference of legume fortified maize-meal porridge," Journal of Food and Nutrition Research, vol. 4, no. 10, pp. 664-670, 2016.

[9] M. Adegunwa, E. Alamu, and L. Omitogun, "Effect of processing on the nutritional contents of yam and cocoyam tubers," Journal of Applied Bioscience, vol. 46, pp. 3086-3092, 2011.

[10] E. Wheeler and R. Ferrel, "A method for phytic acid determination in wheat and wheat fractions," Cereal Chemistry, vol. 48, no. 3, pp. 312-320, 1971.
[11] I. Amoo, O. Adebayo, and A. Oyeleye, "Chemical evaluation of winged beans (Psophocarpus tetragonolobus), Pitanga cherries (Eugenia uniflora) and orchid fruit (Orchid fruit myristica)," African Journal of Food, Agriculture, Nutrition and Development, vol. 6, no. 2, 2006.

[12] M. U. Makeri, F. Abdulmannan, M. A. Ilowefah, C. Chiemela, S. a. M. Bala, and K. Muhammad, "Comparative physicochemical, functional and structural characteristics of winged bean (Psophocarpus tetragonolobus DC) and Soybean (Glycine max.) protein isolates," Journal of Food Measurement and Characterization, vol. 11, no. 2, pp. 835-846, 2017.

[13] A. Banerjee, S. Chanda, B. C. Sasmal, and D. K. Bagchi, "Studies on yield, extracted leaf protein and deproteinised extract of winged bean grown as a biennial crop," Journal of the Science of Food and Agriculture, vol. 37, no. 8, pp. 783-790, 1986.

[14] M. L. Adams, E. Lombi, F.-J. Zhao, and S. P. McGrath, "Evidence of low selenium concentrations in UK breadmaking wheat grain," Journal of the Science of Food and Agriculture, vol. 82, no. 10, pp. 1160-1165, 2002.

[15] M. L. Morris, R. Tripp, and A. A. Dankyi, Adoption and Impacts of Improved Maize Production Technology: A Case Study of the Ghana Grains Development Project, CIMMYT, Mexico City, Mexico, 1999.

[16] K. H. Brown, “The importance of dietary quality versus quantity for weanlings in less developed countries: a framework for discussion," Food and Nutrition Bulletin, vol. 13, no. 2, pp. 86-94, 1991.

[17] S. S. Kantha and J. W. Erdman, "The winged bean as an oil and protein source: a review," Journal of the American Oil Chemists' Society, vol. 61, no. 3, pp. 515-525, 1984.

[18] P. K. Singh, R. D. Ningombam, and J. S. Salam, "Proximate composition and nutritional evaluation of underutilized legume Psophocarpus tetragonolobus (L.) DC. grown in Manipur, Northeast India," American Journal of Food Technology, vol. 7, no. 8, pp. 487-493, 2012.

[19] P. Lepcha, A. N. Egan, J. J. Doyle, and N. Sathyanarayana, “A review on current status and future prospects of winged bean (Psophocarpus tetragonolobus) in tropical agriculture," Plant Foods for Human Nutrition, vol. 72, no. 3, pp. 225-235, 2017.

[20] J. I. Boye, S. Roufik, N. Pesta, and C. Barbana, “Angiotensin I-converting enzyme inhibitory properties and SDS-PAGE of red lentil protein hydrolysates," LWT-Food Science and Technology, vol. 43, no. 6, pp. 987-991, 2010.

[21] M. U. Makeri, R. Karim, M. S. Abdulkarim, H. M. Ghazali, M. S. Miskandar, and K. Muhammad, "Comparative analysis of the physico-chemical, thermal, and oxidative properties of winged bean and soybean oils," International Journal of Food Properties, vol. 19, no. 12, pp. 2769-2787, 2016.

[22] P. S. Misra, G. Misra, D. Prakash, R. D. Tripathi, A. R. Chaudhary, and P. N. Misra, "Assay of some nutritional and antinutritional factors in different cultivars of winged bean (Psophocarpus tetragonolobus (L.) DC) seeds," Qualitas Plantarum Plant Foods for Human Nutrition, vol. 36, no. 4, pp. 367-371, 1987.

[23] O. David, E. Arthur, S. O. Kwadwo, E. Badu, and P. Sakyi, "Proximate composition and some functional properties of soft wheat flour," International Journal of Innovative Research in Science, Engineering and Technology, vol. 4, no. 2, pp. 753-758, 2015.

[24] A. Ahmed, J. Lydia, and J. Campbell, "Evaluation of baking properties and sensory quality of wheat-cowpea flour," Engineering and Technology, vol. 70, p. 2012, 2012. 
[25] G. E. Adukpo, R. Agbemafle, A. Asare, E. Diabor, and M. J. Akonor, "Evaluation of some breeding lines of cowpea for nutritional and functional properties," in Organization for Women in Science for the Developing World (OWSD) 2nd Africa Regional Conference Technical Proceedings, pp. 353-361, Ghana, October 2013.

[26] M. S. Butt and R. Batool, "Nutritional and functional properties of some promising legumes protein isolates," Pakistan Journal of Nutrition, vol. 9, no. 4, pp. 373-379, 2010.

[27] H. W. Leach, L. D. McCowen, and T. J. Schoch, "Structure of starch granules. I. Swelling and solubility patterns of various starches," Cereal Chemistry, vol. 36, pp. 534-544, 1959.

[28] C. Chinma and D. Gernah, "Physicochemical and sensory properties of cookies produced from cassava/soyabean/ mango composite flours," Journal of Food Technology, vol. 5, no. 3, pp. 256-260, 2007.

[29] A. J. Olalekan and B. F. Bosede, "Comparative study on chemical composition and functional properties of three Nigerian legumes (jack beans, pigeon pea and cowpea)," Journal of Emerging Trends in Engineering and Applied Sciences, vol. 1, no. 1, pp. 89-95, 2010.

[30] A. Singh, Y.-C. Hung, M. Corredig, R. D. Phillips, M. S. Chinnan, and K. H. McWatters, "Effect of milling method on selected physical and functional properties of cowpea (Vigna unguiculata) paste," International Journal of Food Science and Technology, vol. 40, no. 5, pp. 525-536, 2005.

[31] G. Eshun, "Nutrient composition and functional properties of bean flours of three soya bean varieties from Ghana," African Journal of Food Science and Technology, vol. 3, no. 8, pp. 176-181, 2012.

[32] Z. Sui, P. W. Lucas, and H. Corke, "optimal cooking time of noodles related to their notch sensitivity," Journal of Texture Studies, vol. 37, no. 4, pp. 428-441, 2006.

[33] M. Z. Islam, M. L. J. Taneya, M. Shams-Ud-Din, M. Syduzzaman, and M. M. Hoque, "Physicochemical and functional properties of brown rice (Oryza sativa) and wheat (Triticum aestivum) flour and quality of composite biscuit made thereof," The Agriculturists, vol. 10, no. 2, pp. 20-28, 2012.

[34] N. H. Tan, Z. H. A. Rahim, H. T. Khor, and K. C. Wong, "Winged bean (Psophocarpus tetragonolobus) tannin level, phytate content and hemagglutinating activity," Journal of Agricultural and Food Chemistry, vol. 31, no. 4, pp. 916-917, 1983.

[35] C. A. Ryan, "Protease inhibitors in plants: genes for improving defenses against insects and pathogens," Annual Review of Phytopathology, vol. 28, no. 1, pp. 425-449, 1990.

[36] Y. Habu, H. Fukushima, Y. Sakata, H. Abe, and R. Funada, “A gene encoding a major Kunitz proteinase inhibitor of storage organs of winged bean is also expressed in the phloem of stems," Plant Molecular Biology, vol. 32, no. 6, pp. 1209-1213, 1996.

[37] A. P. Giri, A. M. Harsulkar, M. S. B. Ku et al., "Identification of potent inhibitors of Helicoverpa armigera gut proteinases from winged bean seeds," Phytochemistry, vol. 63, no. 5, pp. 523-532, 2003.

[38] S. Peyachoknagul, T. Matsui, H. Shibata et al., "Sequence and expression of the mRNA encoding the chymotrypsin inhibitor in winged bean (Psophocarpus tetragonolobus (L.) DC.)," Plant Molecular Biology, vol. 12, no. 1, pp. 51-58, 1989.

[39] N. Parmar, N. Singh, A. Kaur, and S. Thakur, "Comparison of color, anti-nutritional factors, minerals, phenolic profile and protein digestibility between hard-to-cook and easy-to-cook grains from different kidney bean (Phaseolus vulgaris) accessions," Journal of Food Science and Technology, vol. 54, no. 4, pp. 1023-1034, 2017.

[40] A. Jacob, D. Etong, and A. Tijjani, "Proximate, mineral and anti-nutritional compositions of melon (Citrullus lanatus) seeds," British Journal of Research, vol. 2, pp. 142-151, 2015.

[41] U. E. Inyang and V. O. Ekop, "Physico-chemical properties and anti-nutrient contents of unripe banana and African yam bean flour blends," International Journal of Food Sciences and Nutrition, vol. 4, no. 5, pp. 549-554, 2015.

[42] G. O. Ajibola and A. A. Olapade, "Physical, proximate and anti-nutritional composition of African yam bean (Sphenostylis stenocarpa) seeds varieties," Journal of Food Research, vol. 5, no. 2, p. 67, 2016.

[43] S. S. Kantha, N. S. Hettiarachchy, and J. W. Erdman Jr., "Phytic acid, and selected minerals in winged bean flour," Cereal Chemistry, vol. 63, no. 1, pp. 9-13, 1986.

[44] C. S. Yea, A. Ebrahimpour, A. A. Hamid, J. Bakar, K. Muhammad, and N. Saari, "Winged bean (Psophorcarpus tetragonolobus (L.) DC) seeds as an underutilised plant source of bifunctional proteolysate and biopeptides," Food \& Function, vol. 5, no. 5, pp. 1007-1016, 2014.

[45] Y. Afe Dwiani and T. Estiasih, "Functional properties of winged bean (Psophocarpus tetragonolobus (L.)) protein concentrate," International Journal of ChemTech Research, vol. 6, no. 14, pp. 5458-5465, 2014.

[46] J. Halder, D. Kushwaha, R. K. Dubey, A. B. Rai, and B. Singh, "Pest profiling and varietal screening of winged bean (Psophocarpus tetragonolobus): a lesser known green vegetable and grain legume in Eastern Uttar Pradesh, India," Vegetable Science, vol. 45, no. 1, pp. 140-143, 2018.

[47] P. Kaushik, S. Kumar, and M. S. Dhaliwal, "Usefulness of three under exploited vegetable legumes-a review," International Journal of Current Microbiology and Applied Sciences, vol. 7, no. 3, pp. 861-870, 2018. 